\title{
Reintroduction of greater Indian rhinoceros into Dudhwa National Park
}

\author{
John B. Sale and Samar Singh
}

The range of the endangered greater Indian rhinoceros is now restricted to a few isolated pockets. One of the conservation measures recommended for the species is the establishment of additional viable populations in suitable areas. The authors describe an attempt to do this in Dudhwa National Park in Uttar Pradesh, India.

The original distribution of the greater Indian rhinoceros Rhinoceros unicomis spanned the flood plains of the Indus, Ganges and Brahmaputra rivers from the Hindu Kush in the west to the present Indo-Burmese border in the east. Mainly as a result of habitat loss and overhunting, only a few isolated pockets remain in the eastern part of this former range, in the terai of Nepal and West Bengal, and the Brahmaputra

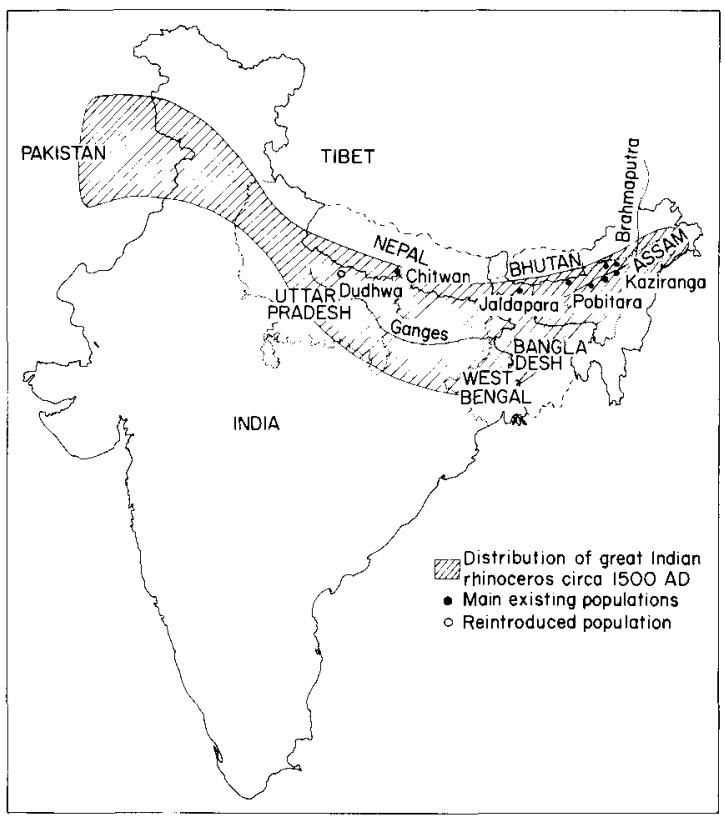

Figure 1. Map showing past and present distribution of the greater Indian rhinoceros.

Reintroduction of greater Indian rhinoceros valley in Assam (Figure 1). Of the present species population of around 1700, approximately 84 per cent are in Kaziranga and Chitwan National Parks (1080 and 350 rhinos, respectively), most of the rest being scattered in small populations. While numbers have greatly increased in Kaziranga since the turn of the century, heavy poaching is a chronic problem there and in other locations. Other serious conservation hazards include large-scale erosion of habitat due to increased flooding resulting from deforestation of catchment areas and epidemic diseases, the likelihood of which is increased by contact with domestic stock and excessively high rhino densities in some populations (Laurie, 1978).

The species is on the IUCN endangered list. A 1979 report of the SSC Asian Rhino Specialist Group (Schenkel and Schenkel, 1979) emphasized the need for continuous effort in the protection and monitoring of the species, adding that 'steps must be envisaged to establish additional viable population units in suitable areas, preferably in the rhino's former distribution range'.

In 1979 the Indian Board for Wildlife set up a committee, under the chairmanship of the senior author, to examine the conservation status of the rhino in India and, if appropriate, to make recommendations for the establishment of several new populations. After field visits to a number of possible reintroduction sites and a careful examination of the existing rhino situation 


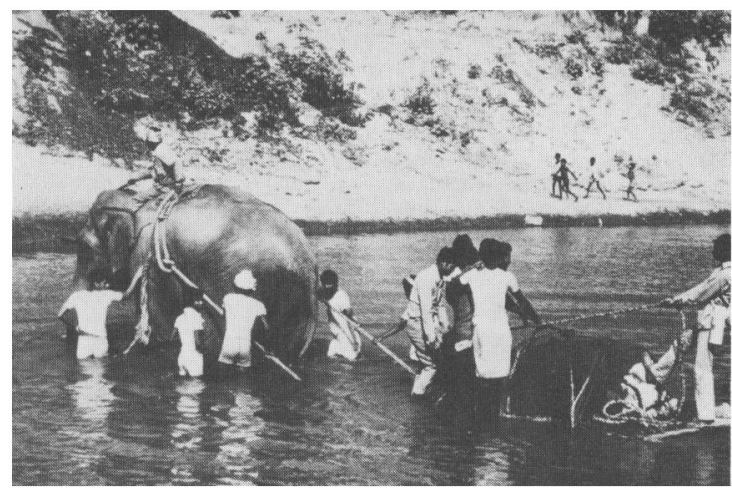

in Assam, the Committee (Sale, 1981) recommended a trial translocation of six animals into Dudhwa National Park in the terai zone of northern Uttar Pradesh. Dudhwa offered the essential prerequisites of swampy grassland habitat under the protection of a well-managed national park. Moreover, there are reports of rhinos in the Dudhwa area within the last 100 years. The suitability of Dudhwa was confirmed by Professor Dr R. Schenkel, Chairman of the SSC Asian Rhino Specialist Group, after a visit to the park in 1980/81 (Schenkel, 1983).

In order to ascertain that the park would provide adequate food for a rhino population, the Committee commissioned a survey of rhino food plants in the proposed reintroduction area by the Botanical Survey of India (Hajra and Shukla, 1982). It was estimated that this $90-\mathrm{sq}-\mathrm{km}$ area could support an ultimate maximum number of 90 rhinos. In addition, there are other areas of good rhino habitat in Dudhwa National Park.

In view of the fact that there was very little experience of modern capture methods with the greater Indian rhinoceros in the wild, experimental capture using drug immobilization was carried out in Assam during 1980 (Sale and Woodford, 1981). These trials established drug dosages, handling and transport procedures for the proposed translocation operation.

In order to prevent released rhinos from wandering out of Dudhwa into adjacent cultivation and to assist their initial establishment in optimal habitat, a 27-sq-km area was enclosed by a two-strand electric fence. A 9-km critical section near the park boundary was additionally pro82

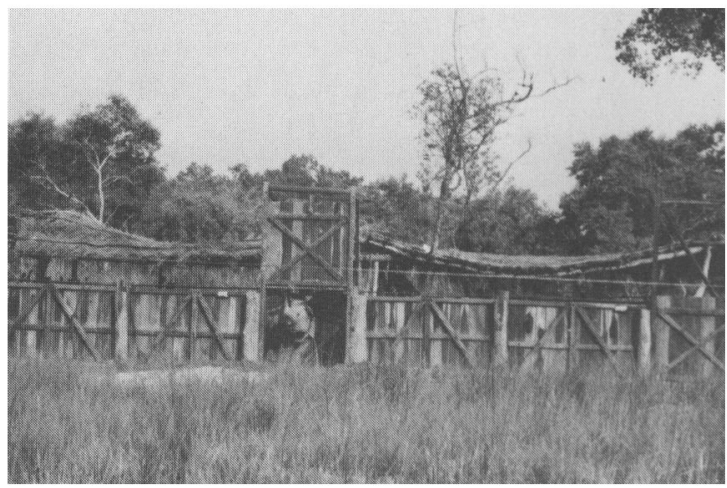

tected against accidental escape by the con struction of a rhino-proof trench outside the electric fence. Holding stockades for the new arrivals were built within the fenced zone, and Dudhwa field staff were sent to Assam for training in rhino management.

\section{The 1984 translocation from Assam}

Early in 1984 a group of about 10 rhinos living outside Pobitara Sanctuary was selected by the Assam Forest Department for the capture operation. The fact that these rhinos were causing considerable damage to cultivated crops and proving difficult to protect adequately (a large adult was poached while the capture team was in the area) provided enhanced justification for the translocation experiment. However, such a small target population limited scope for the selection of six young adult individuals, which would have constituted ideal candidates for withstanding the stresses of capture and translocation. Between 11 and 21 March 1984, six animals were captured by drug immobilization. They were crated, revived, transported to stockades a few kilometres from the capture area and released. After release the animals were encouraged to wallow, and in most cases satisfactory feeding was established within two to three days. Necessary health care, mostly consisting of treatment of superficial lacerations received during capture, was rendered by a team of three veterinarians. The first animal captured, a large male, escaped from its stockade during the night.

On 30 March the five remaining animals (a subadult and two elderly females; a young adult and one older male) were crated, driven in trucks to Oryx Vol 21 No 2, April 1987 


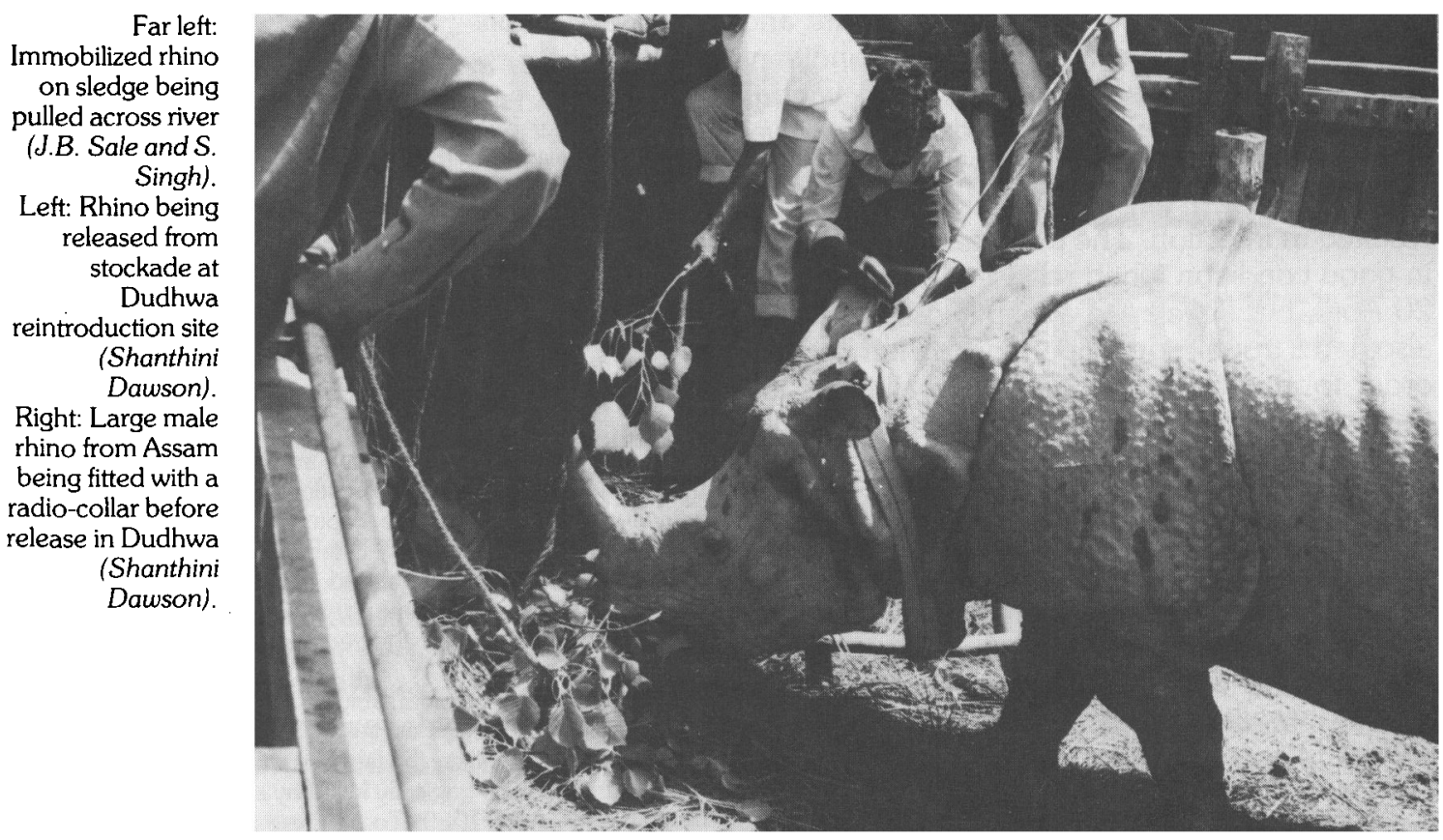

Guwahati Airport and loaded into an Aeroflot IL76 cargo aircraft chartered by the Government of India. Three of the animals were lightly sedated prior to loading and they all remained calm during the two-and-a-half-hour flight from Guwahati to New Delhi. After food and water at Delhi Airport, the rhinos were driven through the night to Dudhwa National Park, where they were uncrated into individual stockades. One female died after 11 days, but the remaining four settled well; three were released from the stockades on 20 April and the large male was released on 9 May, after being fitted with a radio collar.

\section{The 1985 translocation from Nepal}

To establish a vigorous breeding nucleus of rhinos in Dudhwa, it was decided to introduce more stock from a different population. The collaboration of His Majesty's Government of Nepal was obtained in the exchange of four young adult female rhinos, from around the area of Chitwan National Park, for 16 domesticated Indian elephants. By selecting only females, the reproductive potential in Dudhwa would be more than doubled and eventual mating of these Reintroduction of greater Indian rhinoceros animals with the totally unrelated Assam males would ensure maximum genetic vigour.

Capture took place on 28-31 March 1985 in Sauraha just north of Chitwan National Park. All four animals, estimated to be between 5 and 7 years old, were immobilized and sledged into crates in which they were revived. They were immediately driven $720 \mathrm{~km}$ to Dudhwa, and all withstood the 24-hour journey well and, with the exception of the first arrival, which broke out during its first night, quickly settled in the Dudhwa stockades. They were released into the wild after a week.

\section{Survival}

Of the total of nine rhinos translocated to Dudhwa, seven survive in excellent health at the time of writing (December, 1986) and have settled well in the area enclosed by the electric fence. These consist of the young female and both males of the 1984 introduction from Assam, and all four young adult females of the 1985 group from Nepal.

The two elderly females from Assam both died after their arrival in Dudhwa. One of them did not 
feed satisfactorily from the time of capture and remained unsettled, gradually losing condition, despite treatment with vitamins and various appetite stimulants. She died 11 days after arrival in Dudhwa, following the abortion of a dead fetus, which left her very weak and probably resulted in infection. The other adult female was in good condition when released in Dudhwa on 20 April, but developed a limp shortly after and also had a troublesome open sore on her back. In order to investigate and treat both ailments the rhino was immobilized on 7 May. On rising after revival her right forelimb was seen to be paralysed, apparently due to nerve damage while recumbent-a known risk of rhino immobilization (King, 1969). In spite of intensive veterinary attention the animal finally succumbed on 31 July. These elderly females were a poor translocation risk. However, younger females were not available at the designated capture site, and had these two rhinos not been translocated, they would have remained highly vulnerable to poaching.

In addition to special protection measures, the movements of the rhinos in relation to habitat, feeding and social behaviour are being monitored daily by the dedicated Dudhwa Park staff, until recently under the able supervision of Park Director, R. L. Singh.

\section{Conclusion}

There is every hope that the 1984 and 1985 translocations will result in the first viable population of rhinoceros in central north India since the last century. In addition, valuable techniques in the capture and handling of the great Indian rhinoceros were developed (Sale et al., in prep.) which will be useful in the future management of the species in the subcontinent. If the Dudhwa reintroduction experiment proves successful, it will undoubtedly lead to further use of this approach to repopulate selected areas of the rhino's former range, thus reducing the present degree of threat to the species. It is understood that Nepal has recently reintroduced a group from the Chitwan area into Bardia Wildlife Sanctuary in western Nepal, and other reintroduction sites in India are under consideration, including the relocation of some animals within the State of Assam.

84

\section{Acknowledgments}

A great number of persons have assisted in the Dudhwa reintroduction programme. First and foremost is the late Prime Minister of India, Mrs Indira Gandhi, without whose enthusiastic support the project would probably not have materialized. The former Chief Minister of Assam, $\mathrm{Mr}$ Hiteshwar Saikia, the former Union Deputy Minister of Environment, Mr Diguijay Sinh, and the former Forest Minister of Uttar Pradesh, Dr Sanjay Singh, also gave full support to the project in their respective spheres. Professor Dr R. Schenkel, former Chairman, Asian Rhino Specialist Group of SSC/IUCN, gave professional advice on a number of occasions. Mr B. N. Upreti and Dr Hemanta Mishra of the Department of National Parks and Wildlife Conservation, His Majesty's Government of Nepal, arranged the collaboration that made possible the translocation from Chitwan and also actively participated in the capture operation. Successive Chief Wildlife Wardens of Uttar Pradesh and Assam, in particular Mr V. B. Singh and Mr P. C. Das, and their respective staffs, were responsible for many of the detailed arrangements essential to the translocations. Veterinarians $M$. M. Barua, R. K. Das, F. W. Franzmann, S. P. Shrestha, D. H. Soldan and Andrew Soldan ably assisted in the actual capture and care of the rhinos during holding and transportation. Dudhwa Range Officer, the late R. D. Singh, gave dedicated service until he was tragically killed by a tiger while caring for the rhinos in April 1985. To all these colleagues we owe a great debt of gratitude for their contribution to the success of the first rhino reintroduction project in India.

\section{References}

Hajra, P.K. and Shukla, V. 1982. Dudhwa National Park: Some Botanical Aspects of the Proposed New Habitat for Rhino. Botanical Survey of India, Howrah.

King, J.M. 1969. The Capture and Translocation of the Black Rhinoceros. E. Afr. Wildl. J. 7, 115-130.

Laurie, W.A. 1978. The Ecology and Behaviour of the Greater One-horned Rhinoceros. Ph.D. Thesis. University of Cambridge, UK.

Sale, J.B. 1981. Final Recommendations of the Rhino SubCommittee of the Wild Life Status Evaluation Committee of the IBWL, on the Translocation of Great Indian rhinoceros. Government of India, New Delhi. Mimeo.

Sale, J.B. and Woodford, M.H. 1981. Preliminary Report on Drug Immobilisation and Transport of the Great Indian Rhinoceros. Field Document No. 7, Project IND/74/046, India: Crocodile Breeding and Management. FAO, Rome.

Schenkel, R. and Schenkel, L. 1979. SSC Asian Rhino Specialist Group. Special Meeting, Bangkok 13-16 August, 1979. General Report and Synopsis. IUCN, Gland, Switzerland. Mimeo.

Schenkel, R. 1983. Report on the Suitability of Dudhwa National Park, UP, as Potential Site for Re-introduction of the Indian Rhinoceros. IUCN Species Survival Commission, Gland, Switzerland. Mimeo.

John B. Sale, Chief Technical Adviser, FAO Project, Wildlife Institute of India, PO New Forest, Dehra Dun, Uttar Pradesh, India.

Samar Singh, formerly Joint Secretary (Forests and Wildlife) and Director Wildlife Preservation, Government of India, New Delhi, India.

Oryx Vol 21 No 2, April 1987 